\title{
The Control of Human Immunosystem by Using Paeony Root Drug
}

\author{
Hideo Tsuboi ${ }^{1}$, Muhaimin Rifa'i $^{2}$, Khaled Hossain ${ }^{3}$, Izumi Nakashima ${ }^{4}$ and Haruhiko Suzuki ${ }^{5 *}$ \\ 1 Unit of Environmental Health Sciences, Department of Biomedical Sciences, College of Life and Health Sciences, Chubu \\ University, Kasugai-shi, Aichi, Japan \\ 2 Department of Biology, Brawijaya University ,Malang 65145, East Java, Indonesia \\ 3 Department of Biochemistry and Molecular Biology, Rajshahi University, Rajshahi-6205, Bangladesh \\ 4 Unit of Immunology, Department of Biomedical Sciences, College of Life and Health Sciences, Chubu University, Kasugai- \\ shi, Aichi, Japan \\ 5 Department of Immunology, Nagoya University Graduate School of Medicine, Nagoya 466-8550, Japan
}

\begin{abstract}
Paeoniflorin (PF), isolated from paeony root, has been used as a herbal medicine for more than 1200 years in China, Korea and Japan for its anti-allergic, anti-inflamatory and immunoregulatory effects. In this study, we found that PF induces apoptosis in both murine T-lineage cells and human T-cell leukemia Jurkat cells. This apoptosis was mediated through the reduction of mitochondrial membrane potential, activation of caspase and fragmentation of DNA. Interestingly, PF induced generation of reactive oxygen species (ROS) and a reducing agent, dithiothreitol (DTT), and a ROS scavenger, N-acetyl cysteine (NAC), successfully attenuated the PFinduced apoptosis. Additionally, PF induced the phosphorylation of three mitogen-activated protein (MAP) family kinases, extracellular signal-regulated kinase, c-Jun amino-terminal kinase (JNK) and p38 MAP kinase. Curcumin, an anti-oxidant and JNK inhibitor, inhibited PF-induced apoptosis, suggesting the possible involvement of curcumin-sensitive JNK or other redox-sensitive elements in PF-induced apoptosis. These results partially explain the action mechanism of PF-containing paeony root as a herbal medicine.
\end{abstract}

Keywords: paeoniflorin; paeony root; apoptosis; reactive oxygen species (ROS); redox; $\mathrm{CD} 8{ }^{+} \mathrm{CD} 122^{+}$ regulatory $\mathrm{T}$ cells

\section{Introduction}

Paeony root (Paeoniae radix; Shakuyaku in Japanese) is one of the most well-known herbs in China, Korea and Japan and has been used as a medicine for more than 1200 years. Several ingredients have been extracted from the paeony root, including oxypaeoniflorin, albiflorin, benzoylpaeoniflorin and paeoniflorin [12, 22, 29]. Among them, paeoniflorin (PF), a glucoside, is known to be one of the principle bioactive components of paeony root [31]. PF has been reported to have immunoregulatory [16], antiallergic [34], anti-inflammatory [34], cognitionenhancing [23], neuromuscular-blocking [13, 14], anti-convulsant [2], anti-hyperglycemic [10], anticoagulant [11], and sedative [30] effects. Preparations of more than 40 kampo (Chinese and Japanese traditional) medicines contain

\footnotetext{
*Corresponding address:

Dr. Haruhiko Suzuki,

Department of Immunology, Nagoya University

Graduate School of Medicine, 65 Tsurumai-cho,

Showa-ku, Nagoya 466-8550, Japan.

Telephone : +81-52-744-2135

Fax : +81-52-744-2972

E-mail : k46200a@nucc.cc.nagoya-u.ac.jp
}

paeony root. Although paeony root or PF as its principle component is one of the main constituents of many kampo medicines, the mechanism by which it elicits immunoregulatory action has not been elucidated. In this study, we found that PF induces apoptosis in both murine T-lymphocytes and human T-cell leukemia Jurkat cells through a redox-linked mechanism. PF-induced apoptosis is mediated by the activation of caspase followed by the fragmentation of DNA. We also found that PF induces reduction of mitochondrial membrane potential and production of reactive oxygen species (ROS), which may act as a second messenger for transducing the PF-mediated proapoptotic signals.

\section{Materials and Methods Cells, Reagents and Antibodies}

PF $\left[\mathrm{C}_{23} \mathrm{H}_{28} \mathrm{O}_{11}, \mathrm{MW}: 480.47\right.$, purity: $93.0 \%$ (HPLC), LD50: $9530 \mathrm{mg} / \mathrm{kg}$ ] was purchased from Wako Biochemicals (Osaka, Japan). Single cell suspensions of murine thymocytes and splenocytes were prepared from 6-8-wk-old C57BL/6 strain mice. Splenic T cells (a T-cellenriched fraction) were obtained by passing spleen cells through a nylon wool column 
according to the technique described previously [19]. A Jurkat cell line (human T-cell leukemia cells), a NIH 3T3 cell line (murine fibroblasts), a SK Hep1 cell line (human hepatoma cells) and a COS-7 cell line (monkey kidney fibroblasts) were also used. The cells were cultured in RPMI-1640 for thymocytes, splenocytes and Jurkat cells or in DMEM for other cell lines (Nissui Pharmaceutical Co., Tokyo, Japan), each supplemented with $10 \%$ heat-inactivated fetal bovine serum (FBS), $100 \mu \mathrm{g} / \mathrm{ml}$ penicillin and $100 \mu \mathrm{g} / \mathrm{ml}$ streptomycin (complete RPMI-1640 or DMEM) at $37^{\circ} \mathrm{C}$ in a humidified atmosphere of $5 \% \quad \mathrm{CO}_{2}$ and $95 \%$ air. Thymocytes or splenocytes $\left(5.0 \times 10^{6} /\right.$ well $)$ and cell lines $(1.0 \times$ $10^{6} /$ well) were placed in each well of a 6 - or 12 well plate containing $1 \mathrm{ml}$ complete RPMI-1640 or DMEM in the presence or absence of PF dissolved in PBS. PBS was added to control cultures. Curcumin, dithiothreitol (DTT), Nacetyl cysteine (NAC), hydroethidine (HE) and carbamoyl cyanide m-chlorophenyl hydrazone (mClCCP) were purchased from Sigma Chemical Co. (St. Louis, MO, USA), and 3,3'dihexyloxacarbocyanine iodide $\left(\mathrm{DiOC}_{6}\right)$ was obtained from Molecular Probes (Eugene, OR). Polyclonal anti-phospho-p42/44MAPK (ERK), anti-phospho-JNK, anti-phospho-p38 and anticleaved caspase 3 antibodies were purchased from New England Biolabs (Beverly, MA), and the monoclonal anti-pan ERK antibody was purchased from Transduction Laboratories (Lexington, KY). Monoclonal anti-p38 and polyclonal anti-JNK antibodies were obtained from Santa Cruz Biotechnology (Santa Cruz, $\mathrm{CA}$ ), and polyclonal anti-poly (ADP-ribrose) polymerase (PARP) antibody was obtained from Upstate Biotechnology (Lake Placid, NY).

\section{SDS-PAGE and Immunoblotting}

SDS-PAGE and immunoblotting were performed as described previously [1]. Briefly, cells were lysed by adding an equal volume of a two-fold concentrated sample buffer $(125 \mathrm{mM}$ Tris- $\mathrm{HCl}, \mathrm{pH}$ 6.8, 4\% SDS, 10\% 2-ME, $20 \%$ glycerol), and proteins thus obtained were subjected to SDS-PAGE with 10\% gel. The proteins were then transferred to a polyvinylidene difluoride membrane. The membrane was incubated with blocking buffer $(5 \%$ non-fat dry milk or $3 \%$ bovine serum albumin) at $4{ }^{\circ} \mathrm{C}$ overnight and then incubated with a specific first antibody for 2-3 hours at room temperature. After washing, the membrane was again incubated with goat anti- rabbit or anti-mouse $\operatorname{IgG}$ conjugated to horse radish peroxidase (Tago, Burlingame, CA) for 12 hours at room temperature. The proteins in the membrane were visualized by Western Blot Chemiluminescence Reagent (DuPont-NEN, Boston, MA) according to the directions of the manufacturer. For reprobing, the membrane was stripped (2\% SDS, $62.5 \mathrm{mM}$ Tris, pH 6.8, 100 $\mathrm{mM}$ 2-ME, $50{ }^{\circ} \mathrm{C}, 30 \mathrm{~min}$ ) and reprobed with the desired antibody. The molecular sizes of the developed proteins were estimated by comparison with prestained protein markers (New England Biolabs, Beverly, MA).

\section{Analysis of DNA Fragmentation by Agarose Gel Electrophoresis}

Cells were lysed in $100 \mu \mathrm{l}$ of hypotonic lysing buffer $(50 \mathrm{mM}$ Tris- $\mathrm{HCl}, 0.5 \%$ SDS, $10 \mathrm{mM}$ EDTA), followed by addition of $2 \mu$ of proteinase $\mathrm{K}(20 \mathrm{mg} / \mathrm{ml})$ and $6 \mu \mathrm{l}$ of RNAse (10 $\mathrm{mg} / \mathrm{ml}$ ). The resultant mixture was incubated at $55^{\circ} \mathrm{C}$ for $1 \mathrm{~h}$. A sample $(10 \mu \mathrm{l})$ was mixed with 3 $\mu \mathrm{l}$ of $0.25 \%$ (w/v) bromophenol blue and $40 \%$ $(\mathrm{w} / \mathrm{v})$ sucrose and was then run on $1.5 \%$ agarose gel with $0.1 \mu \mathrm{g} / \mathrm{ml}$ ethidium bromide [1].

\section{Flow Cytometric Analysis of Mitochondria} Membrane Potential $\left(\Delta \Psi_{\mathrm{m}}\right)$ Disruption

Mitochondria membrane potential analysis was performed as described previously $[17,37$, 38]. In short, cells were collected and washed twice with PBS. The cells were incubated in 500 $\mu \mathrm{l}$ of PBS containing $50 \mathrm{nM} \mathrm{DiOC} 6$ for $30 \mathrm{~min}$. This DiOC $_{6}$ cyanine dye accumulates in the mitochondrial matrix under the influence of the $\Delta \Psi_{\mathrm{m}} . \quad \mathrm{DiOC}_{6}$ membrane potential-related fluorescence was analyzed using a FACScalibur flow cytometer.

\section{Analysis of ROS Production by Flow Cytometry (FCM)}

For measurement of the level of ROS production by $\mathrm{PF}$, cells were incubated with or without $500 \mu \mathrm{g} / \mathrm{ml} \mathrm{PF}$ for $1-4 \mathrm{~h}$ (thymocytes) or 2-6 h (Jurkat cells) at $37^{\circ} \mathrm{C}$. The cells were then stained with $2 \mu \mathrm{M}$ hydroethidine (HE) for 15 min at $37^{\circ} \mathrm{C}$. Thereafter, cells were kept on ice until cytofluorometric analysis within $60 \mathrm{~min}$. Analysis was performed by FCM (EPICS profile; Coulter, Hialeah, FL). Forward and side light scatters were gated on the major population of normal-sized lymphoid cells. Generation of superoxide anion was measured as described previously $[26,35]$. 


\section{Reproduction of the Experiments}

At least three independent experiments were performed for each assay. Representative results of the experiments are shown in Figures 1-6.

\section{Results}

PF Induces Apoptosis with DNA Fragmentation in Murine T-Lineage Cells and Human T-cell Leukemia Jurkat Cells

We first investigated whether PF induces DNA fragmentation in murine $\mathrm{T}$ lymphocytes and human T-cell leukemia Jurkat cells. As shown in Figure 1A-1D, PF induced fragmentation of DNA in murine thymocytes, spleen cells, splenic $\mathrm{T}$ cells and Jurkat cells in a concentration-dependent manner. DNA fragmentation was also induced in some (Figure 1E) but not all non-T-cell lines (Figure 1F, 1G). These results suggest that sensitivity to PF depends on cell type and that T-lineage cells are included in the highly sensitive group.

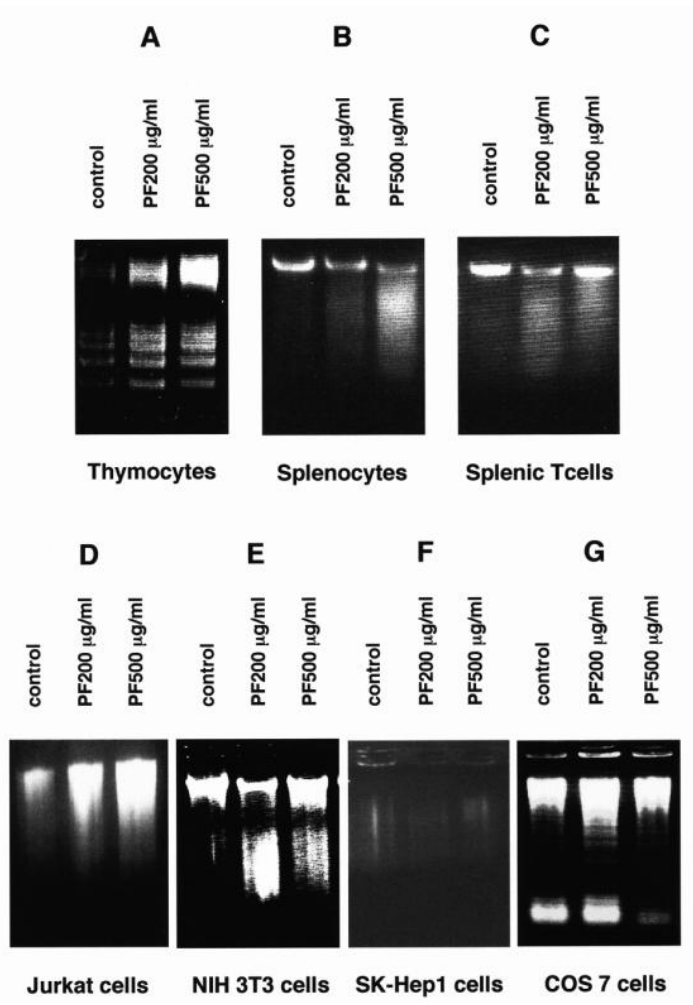

Figure 1. PF induces DNA fragmentation in T-lineage cells. Murine thymocytes (A), murine splenocytes (B), murine splenic $\mathrm{T}$ cells (C), human T-cell leukemia Jurkat cells (D), murine fibroblast NIH 3T3 cells (E), human hepatoma SK-Hep1 cells (F) and monkey kidney fibroblast COS 7 cells $(G)$ were incubated at $37^{\circ} \mathrm{C}$ with or without the indicated concentrations of PF for 14 hours (A) or 20 30 hours (B-G). These cells were then lysed in hypotonic lysing buffer, and DNAs were then analyzed by $1.5 \%$ agarose gel electrophoresis, stained with ethidium bromide, and photographed by UV illumination.

\section{PF Promotes Phosphorylation of MAPK Family Members}

The members of the MAPK family that are activated by dual phosphorylation on both tyrosine and threonine residues have been implicated in the transduction of a wide variety of extracellular signals [8, 27, 28]. Therefore, we next tested whether PF promotes phosphorylation of three classes of MAPK family kinases (ERK, JNK, and p38). As shown in Figure 2, PF dose- and time-dependently increased the phosphorylation of ERK and JNK in murine thymocytes. We obtained the same results in Jurkat cells (data not shown). PF also promoted phosphorylation of $\mathrm{p}-38 \mathrm{MAPK}$ in a manner similar to that for JNK (data not shown).
A

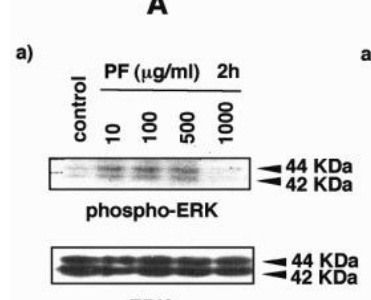

b)

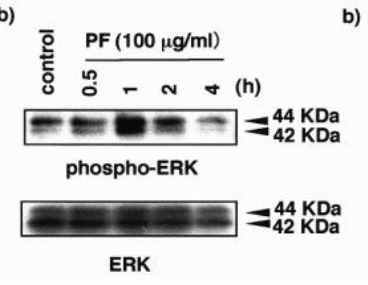

B
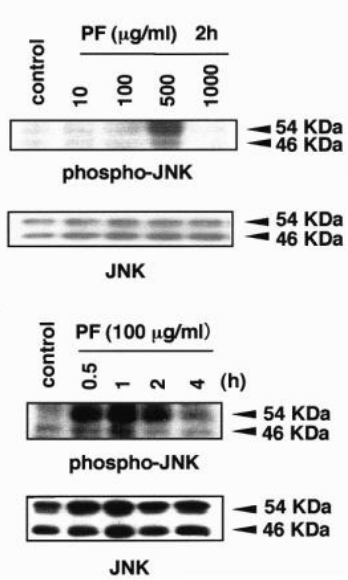

Figure 2. PF induces phosphorylation of ERK and JNK Thymocytes were incubated with or without the indicated concentrations of PF for 2 hours (a) or with $100 \mu \mathrm{g} / \mathrm{ml}$ of PF for the indicated times (b) at $37{ }^{\circ} \mathrm{C}$. These cells were then lysed and subjected to immunoblot assay with anti-phospho-ERK antibody (A) or anti-phospho-JNK antibody (B). The membranes were stripped and reprobed with corresponding antibodies specific to ERK or JNK. Positions of respective ERKs and JNKs are shown on the right of each panel.

PF-Induced Apoptosis Accompanies the Reduction of Mitochondrial Membrane Potential $\left(\Delta \Psi_{\mathrm{m}}\right)$

It has been reported that mitochondria play a key role in apoptosis induction, exhibiting major changes in their structure and function $[6,7,21]$. It is known that decrease in mitochondrial membrane potential $\left(\Delta \Psi_{\mathrm{m}}\right)$, which is caused by a local disruption of the outer mitochondrial membrane $[17,35,37]$, is an early central event of apoptotic cell death [33]. We measured the level of in $\Delta \Psi_{\mathrm{m}}$ cells treated with PF by the 
uptake of a membrane potential-sensitive dye, $\mathrm{DiOC}_{6}$. As shown in Figure 3, treatment of murine thymocytes or Jurkat cells with 500 $\mu \mathrm{g} / \mathrm{ml}$ of PF for 4 hours induced reduction in mitochondrial membrane potential.

\section{A}

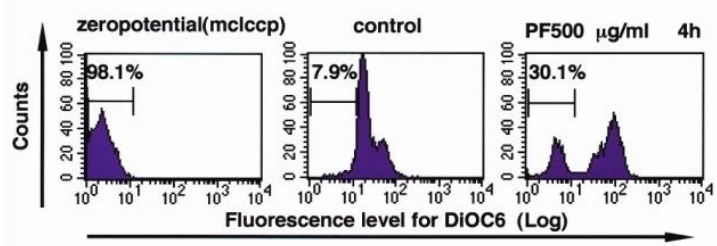

Thymocytes

B

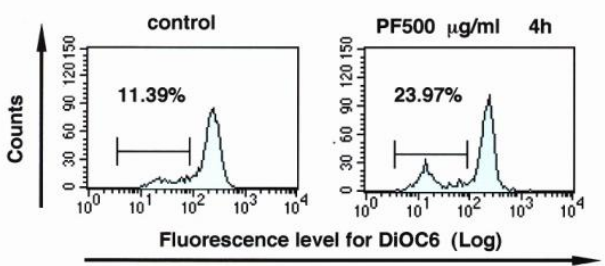

Jurkat cells

Figure 3. PF reduces mitochondrial transmembrane potential $\left(\Delta \Psi_{\mathrm{m}}\right)$. Thymocytes (A) and Jurkat cells (B) were treated with or without $500 \mu \mathrm{g} / \mathrm{ml}$ of $\mathrm{PF}$ for 4 hours at $37{ }^{\circ} \mathrm{C}$, stained by incubation with $\mathrm{DiOC}_{6}(40 \mathrm{nM})$, and subjected to cytofluorometric analysis. To determine zero potential, cells were incubated with mClCCP, an uncoupler that almost completely abolished $\Delta \Psi_{\mathrm{m}}$. The range shown by a horizontal line indicates "negative staining".

\section{PF Induces ROS Production}

Apoptosis is frequently accompanied by the generation of reactive oxygen species (ROS), possibly in mitochondria of which membrane potential is reduced. ROS may act as a second messenger of the intracellular signal for the regulation of cell growth and death induced by a number of elements, including oxidative stresses, cytokines, and growth factors [3, 18, 24, 39]. Therefore, we performed an experiment to see whether PF induces ROS production in Tlineage cells. PF-treated and -untreated cells were labeled with HE, which is known to be oxidized by ROS to ethidium, for emitting red fluorescence. As shown in Figure 4, PF induced ROS production, which was sustained during an incubation period of $1 \sim 4$ hours in murine thymocytes and for a period of $2 \sim 6$ hours in Jurkat cells.
A

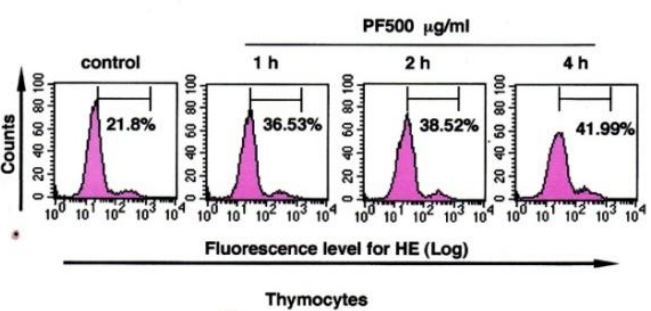

B

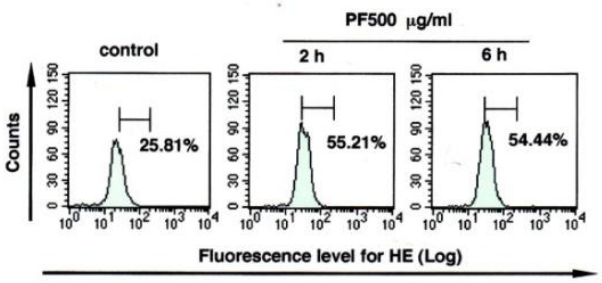

Jurkat cells

Figure 4. PF induces superoxide production. Thymocytes (A) or Jurkat cells (B) were incubated with or without $500 \mu \mathrm{g} / \mathrm{ml}$ PF for 1-4 hours (thymocytes) or $2-6$ hours (Jurkat cells) at $37^{\circ} \mathrm{C}$. The cells were then labeled with $\mathrm{HE}(2 \mu \mathrm{M})$ for $15 \mathrm{~min}$ at $37^{\circ} \mathrm{C}$ and subjected to cytofluorometric analysis. The range shown by a horizontal line indicates "positive staining".

\section{PF Induces Caspase Activation}

We next examined whether PF-induced apoptosis involves activation of caspase, a known key enzyme to mediate DNA fragmentation. As shown in Figure 5A, PF induced caspase- 3 activation in murine thymocytes and splenocytes in a concentrationdependent manner, as demonstrated by degradation of PARP (poly(ADP-ribose) polymerase) $(116 \mathrm{KDa})$, an intracellular substrate of caspase-3, to $85-\mathrm{KDa}$ fragments. Correspondingly, PF time-dependently promoted cleavage of caspase- 3 for activation in murine thymocytes (Figure 5B). PARP degradation was also induced in the $\mathrm{T}$ lymphocytes-enriched fractions of spleen cells and Jurkat cells (Figure 5C and data not shown).

\section{PF Induces Apoptosis through a Redox-} Linked and Curcumin-Sensitive Pathway

The results we obtained suggested that production of ROS in linkage to mitochondrial dysfunction and activation of JNKs by ROS [32] are involved in signaling for PF-induced apoptotic cell death of T-lineage cells. To investigate the possible role of oxidative stress and JNK in PF-induced apoptosis, we treated 
the Jurkat cells with a reducing agent, DTT, which clearly inhibited PF-induced ROS production (data not shown) and a JNK / oxidative stress-mediated signal inhibitor, curcumin $[4,5]$, before adding PF. As shown in Figure 5C, both DTT and curcumin clearly inhibited PF-induced PARP degradation.

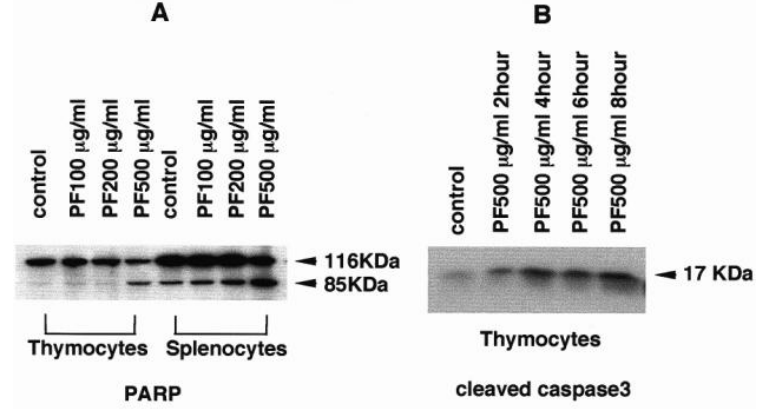

C

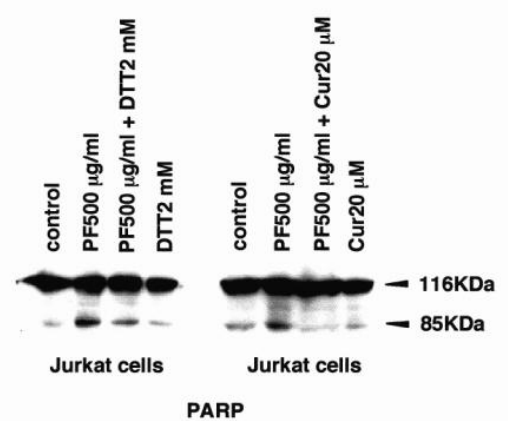

Figure 5. PF induces PARP degradation and caspase 3 cleavage through a redox-linked mechanism. Thymocytes, splenocytes and Jurkat cells were incubated with or without the indicated concentration of PF at $37{ }^{\circ} \mathrm{C}$ for 10 hours. These cells were then lysed with sample buffer and subjected to immunoblot assay with anti PARP antibody (A and C) and anti-cleaved caspase 3 antibody (B). In some groups in (C), DTT $(2 \mathrm{mM})$ or curcumin $(20 \mu \mathrm{M})$ was added $1 \mathrm{~h}$ before the addition of PF. The positions of undegraded (116 KDa) and degraded (85 KDa) PARP molecules and cleaved caspase 3 molecules are shown on the right of the panel.

\section{Attenuation of ROS Production Inhibits PF- Induced Apoptosis}

To determine the role of ROS in PF-induced apoptosis, we pretreated the murine thymocytes or Jurkat cells with an anti-oxidant and ROS scavenger, NAC or DTT, before the addition of PF. As shown in Figure 6, pretreatment of cells with NAC or DTT, which inhibited PF-induced ROS production (data not shown), clearly attenuated PF-induced DNA fragmentation. These results suggested that PF induces ROS production as an early event for activating the apoptotic machinery of the cells.
A
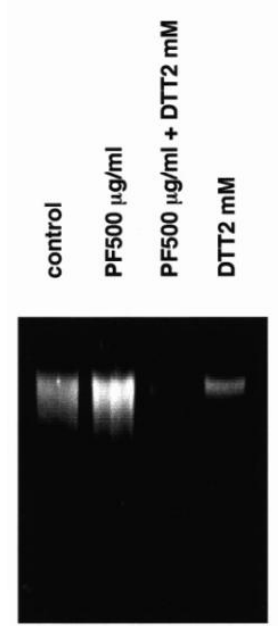

Jurkat cells
B
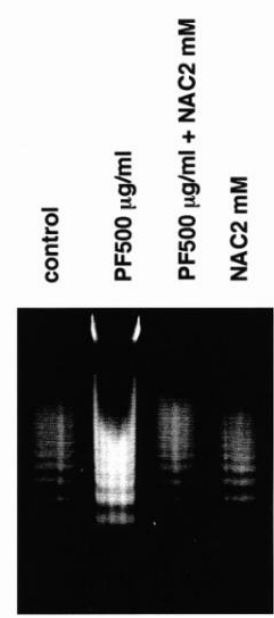

Thymocytes
Figure 6. Reducing agents inhibit PF-induced DNA fragmentation. Thymocytes (A) and Jurkat cells (B) were incubated with or without $500 \mu \mathrm{g} / \mathrm{ml} \mathrm{PF}$ for $14 \mathrm{~h} \mathrm{(A)} \mathrm{24} \mathrm{h} \mathrm{(B)} \mathrm{at} 37{ }^{\circ} \mathrm{C}$. In some groups, $2 \mathrm{mM}$ DTT (A) or NAC (B) was added $1 \mathrm{~h}$ before the addition of PF. The cells were then lysed in hypotonic lysing buffer, and DNAs were then analyzed by $1.5 \%$ agarose gel electrophoresis, stained with ethidium bromide, and photographed by UV illumination.

\section{Discussion}

In this study, we, for the first time, demonstrated that $\mathrm{PF}$, the principal bioactive component of paeony root, which is used in kampo medicine, induces apoptosis in both murine T-lineage cells and human $\mathrm{T}$-cell leukemia Jurkat cells. This apoptosis occurred through activation of caspase (Figure 5) and fragmentation of DNA (Figure 1). The most intriguing finding of this study is that the pharmaceutical action of $\mathrm{PF}$ is linked to the action of oxidative stress. We found that just like arsenic [9] PF induced both reduction of mitochondrial membrane potential and ROS production as an early event for apoptosis induction. Inhibition of ROS production by anti-oxidants such as DTT (Figure 6A) and NAC (Figure 6B) almost completely attenuated PF-induced apoptosis, suggesting that ROS production is a prerequisite for PF-induced apoptosis. Moreover, we found that PF induces phosphorylation of MAPK family proteins, ERK, JNK, and p-38 MAPK, in a time- and concentration- dependent manner (Figure 2). It has been reported that phosphorylation (activation) of JNK is involved in oxidative stress-mediated induction of apoptosis of cells $[25,32]$ and that ASK1, an element upstream of JNK, is activated by oxidative stress [32]. Particularly because PF-mediated apoptosis was 
prevented by curcumin as a JNK/oxidative stress-mediated signal inhibitor, the PF-triggered signal transduction cascade seems to include ROS production, ASK1 activation and JNK activation for subsequent mitochondrial membrane potential reduction, which leads to further ROS production, caspase activation, and DNA fragmentation. An earlier study showed that PF stimulates the adenosine A-1 receptor, which in turn activates PI-3 kinase-dependent PKC [15]. Additionally, we have also observed that PF activates the PI-3 kinase-dependent Akt pathway. Therefore, PF seems to stimulate multiple signaling pathways for diverse cellular functions.

Is there any correlation between the demonstrated action of PF for inducing apoptosis in vitro and its pharmacological action in vivo? Our preliminary experiment in which C57BL/6 mice were given daily injections of PF (200 $\mu \mathrm{g} /$ mouse) for 7 days for measurement of cell population distribution in mice demonstrated that this amount of PF, which was not lethally toxic to mice, induced changes in the distributions of populations and subpopulations of lymphocytes and granulocytes in the spleen and bone marrow (Tsuboi et al., unpublished observation). These results suggest that $\mathrm{PF}$ affects the balance among the population and subpopulations of blood cells in mice, possibly through induction of apoptosis in different populations and subpopulations of blood cells to distinct extents. They may partially explain the mechanism of the anti-allergic or the antiinflammatory or immunoregulatory effect of PFcontaining paeony root. On top of these results, our recent study showed that PF also affects regulatory type $\mathrm{T}$ cells of mice. In other study, we independently found and showed regulatory actions in murine $\mathrm{CD} 8{ }^{+} \mathrm{CD} 122^{+} \mathrm{T}$ cells [40]. With flow cytometry and cell sorting analysis, we recognized that $\mathrm{PF}$ promoted the regulating function of $\mathrm{CD}^{+}{ }^{+} \mathrm{CD} 122{ }^{+} \mathrm{T}$ cells, which reduced IFN- $\gamma$ production of $\mathrm{CD} 8{ }^{+} \mathrm{CD} 122^{-}$ (non-regulatory type) $\mathrm{T}$ cells, while activated IL10 production in $\mathrm{CD} 8{ }^{+} \mathrm{CD} 122^{+} \mathrm{T}$ cells. And these regulatory actions of this $\mathrm{CD} 8{ }^{+} \mathrm{CD} 122^{+} \mathrm{T}$ cells were completely linked with the concentration of PF (Tsuboi et al., unpublished observation). These results suggest that there is high possibility of using $\mathrm{PF}$ as a new type medicine for treatment of some kinds of immuno diseases in future, by which control human immuno system. However, further study is needed to confirm the relationships between the demonstrated PF-induced signaling events and their ultimate pharmacological effects in vivo.

The concentrations of PF we used (100 500 $\mu \mathrm{g} / \mathrm{ml}$ ) in in vitro experiments do not seem to be attained in vivo when a herbal medicine is given to animals or humans. Paeony root is clinically used at 9 12 g/day for humans, and the content of $\mathrm{PF}$ in paeony root is $2 \sim 6 \%$. Therefore, the lowest concentration that was effective in our in vitro experiments $(100 \mu \mathrm{g} / \mathrm{ml}$, which would correspond to $7 \mathrm{~g} / 70 \mathrm{~kg}$ man) was 10 -40-times higher than the clinical human dosage. It is, however, difficult to adequately compare the conditions for the chemicals to display their pharmacological actions in vivo and in vitro, particularly because herbal medicine is usually effective when it is administered for a long time as a mixture of various kinds of chemicals that may work synergistically even if concentrations of individual chemicals are low. It might thereby be that an unusually high concentration of PF is needed for displaying a pharmacological action in an in vitro system in which it affects cells for a short time in the absence of other potentially supporting chemicals. In fact, the effective concentration of $\mathrm{PF}$ for $\mathrm{T}$-cell subpopulation change in the spleen in our preliminary in vivo experiments $(200 \mu \mathrm{g} /$ day/mouse $)$ is within the calculated clinical human dosage of PF (80-300 $\mathrm{mg} /$ day/man).

\section{Acknowledgments}

We are grateful to Mr. T. Ohata, Mr. Y. Kawamoto and Mrs. A. T. Endarti for their helpful advice. We also thank Mrs. H. Saeki, Ms. N. Taniguchi and Mrs. M. Tsuboi for their technical assistance.

\section{References}

[1] Akhand AA, Kato M, Suzuki H, Miyata T, Nakashima I. Level of $\mathrm{HgCl}_{2}$-mediated phosphorylation of intracellular proteins determines death of thymic T-lymphocytes with or without DNA fragmentation. I Cell Biochem Nov1: 1998; 71(2):243-253.

[2] Atef AA, Meselhy RM, Nakamura N, Hattori M, Watanaba H, Murakami Y, Mahamoud AE, Nadia M, Mahfouz and Tarek AM. Anticonvulsant activity of paeonimetabolin-I adducts obtained by incubation of paeoniflorin and thiol compounds with lactobacillus brevis. Biol Pharm Bull 1999; 22(5):491-497.

[3] Chandra J, A. Samari, S. Orrenius. Triggering and modulation of apoptosis by oxidative stress. Free Radical Biol Med 2000; 29:323-333. 
[4] Chen YR, Tan TH. Inhibition of the c-Jun Nterminal kinase(JNK) signaling pathway by curcumin. Oncogene 1998; 17:173-178.

[5] Chen YR, Wang X, Templeton D, Davis RJ, Tan, $\mathrm{TH}$. The role of c-jun $\mathrm{N}$-terminal kinase(JNK) in apoptosis induced by ultraviolet $\mathrm{C}$ and gamma radiation. J Biol Chem 1996; 271:31929-31936.

[6] Desagher S, Martinou JC. Mitochondria as the central control point of apoptosis. Trends Cell Biol 2000; 10:369-377.

[7] Green DR, Reed JC. Mitochondria and apoptosis. Science 1998; 281:1309-1312

[8] Guan KL. Themitogen activated protein kinase signal transduction pathway from the cell surface to the nucleus. Cell Signalling 1994; 6:581-589.

[9] Hossain K, Akhand AA, Kato M, Du J, Takeda K, Wu J, Takeuchi K, Liu W, Suzuki H, Nakashima I. Arsenite induces apoptosis of murine $\mathrm{T}$ lymphocytes through membrane raft-linked signaling for activation of c-jun amino-terminal kinase. J. Immunol. 2000; 165:4290-4297.

[10] Hsu FL, Lai CW, Cheng JT. Antihyperglycemic effects of paeoniflorin and 8-debenzoylpaeoniflorin, glucosides from the root of Paeonia lactiflora. Planta Med 1997; 63:323-325.

[11] Ishida H, Takamatsu M, Tsuji K, Kosuge T. Studies on active substances in herbs used for Oketsu('stagnant blood') in Chinese medicine. On the anticoagulative principle in Paeoniae Radix. Chem Pharm Bull (Tokyo) 1987; 35:849-852.

[12] Kaneda, M., Iitaka, Y., Shibata, S.; Chemical studies on the oriental plant drugs. X X X III. The absolute structure of paeoniflorin, albiflorin, oxypaeoniflorin, and benzoylpaeoniflorin isolated from Chinese paeony root. Tetrabedron 1972; 28 : 4309-4317.

[13] Kimura M, Kimura I, Muroi M, Nakamura T, Shibata S. Depolarizing effects of glycyrrhizin-derivatives relating to the blend effects with paeoniflorin in mouse diaphragm muscle. Japan J Pharmacol 1986; 41:263-265.

[14] Kimura M, Kimura I, Takahashi K, Muroi M, Yoshizaki M, Nanaoka M, Kitagawa M. Blocking effects of blended paeoniflorin or its related compounds with glycyrrhizin on neuromuscular junctions in frog and mouse. Japan J Pharmacol 1984; 36:275-282.

[15] Lai CW, Hsu FL, Cheng JT. Stimulatory effect of paeoniflorin on adenosine A-1 receptors to increase the translocation of protein kinase $\mathrm{C}(\mathrm{PKC})$ and glucose transporter(GULT 4) in isolated rat white adipocytes. Life Sciences 1998; 62 Nos 17/18: 1591 1595.
[16] Liang J, Zhou A, Chen M, Xu S. Negatively regulatory effects of paeoniflorin on immune cells. Eur J Pharmacol 1990; 183:901-902.

[17] Marzo I, Brenner C, Zamzami N, Susin SA, Beutner G, Brdiczka D, Remy R, Xie ZH, Reed JC, Kroemer G. The permeability transition pore complex: a target for apoptosis regulation by caspases and Bcl-2-related proteins. J Exp Med 1998; 187:1261-1271.

[18] Mikami M, Yamazaki M, Yuri S. Kinetical analysis of tumor cell death-inducing mechanism by polymorphonuclear leukocyte-derived calprotectin: involvement of protein synthesis and generation of reactive oxygene species in target cells. Microbiol Immunol 1998; 42(3):211-221.

[19] Nakashima I, mizoguchi K, Kato N, Nagase F, Isobe K, Salto M, Suzuki K. Control of primary IgM antibody responses to $\mathrm{H}-2$ alloantigens by antigenbearing live B lymphocytes. Eur J Immunol 1982; 12 : 713-719.

[20] Nakashima I, M. Y. Pu, Hamaguchi T, Iwamoto S, M. Rahman, Y. H. Zhang, M. Kato, K. Ohkusu, Y. Katano, T. Yoshida. Pathway of signal delivery to murine thymocytes triggered by co-crosslinking CD3 and Thy-1 for cellular DNA fragmentation and growth inhibition. J. Immunol. 1993; 151:3511-3520.

[21] Nicholls DG, Budd SL. Mitochondria and neuronal survival. Physiol Rev 2000; 80:315-360.

[22] Nishizawa M, Yamagishi T, Horikoshi T, Honma N. Chemical studies on Paeoniae Radix(part I ): quantitative determination of glucosides inPaeoniae Radix. Shoyakugaku Zasshi 1979; 33:65-71.

[23] Ohta H, Jian-Wei NI, Matsumoto K, Watanabe H, Shimizu M. Peony and its major constituent, paeoniflorin, improve radial maze performance impaired by scopolamine in rats. Pharm Biochem and Behavior 1993; 45:719-723.

[24] Pani G, Colavitti R, Bedogni B, Anzevino R, Borrello S, Galeotti T. A redox signaling mechanism for density-dependent inhibition of cell growth. The Journal of Biological Chemistry 2000; 275. No. 49:3889138899 .

[25] Ramachandiran S, Huang Q, Dong J, Lau SS, MonksTJ. Mitogen-activated protein kinases contribute to reactive oxygen species-induced cell death in renal proximal tubule epithelial cells. Chem Res Toxicol 2002; 15:1635-1642.

[26] Rothe G, Valet G. Flow cytometric analysis of respiratory burst activity in phagocytes with hydroethidine and 2',7'-dichlorofluorescin. J Lenkocyte Biol 1990; 47:440-448.

[27] Sakata N, Patel HR, Arrufo A, Johnson GL, Gelfand EW. Selective activation of c-jun kinase mitogen- 
activated protein kinase by CD40 on human B cells. $J$ Biol Chem 1995; 270:30823-30828.

[28] Seger R, Krebs EG. The MAPK signaling cascade. FASEB J 1995; 9:726-735.

[29] Shibata S, Nakamura M, Aimi N. Studies on the constituents of Japanese and Chinese crude drugs. VIII. Paeoniflorin, a glucoside of Chinese paeony root.(1) Chem Pharm Bull (Tokyo) 1963; 11:372-378.

[30] Takagi K, Harada M. Pharmacological studies on herb paeony root. II. Anti-inflammatory effect, inhibitory effect on gastric juice secretion, preventive effect on stress ulcer, anti-diuretic effect of paeoniflorin and combined effects with licorice component FM 100. Yakugaku Zasshi 1969; 89:887892

[31] Takagi K, Harada M. (abstract in English) Pharmacological studies on herb paeony root. I. Central effects of paeoniflorin and combined effects with licorice component FM100. Yakugaku Zasshi 1969; 89:879-886.

[32] Takeda K, Matsuzawa A, Nishitoh H, Ichijo H. Roles of MAPKKK ASK1 in stress-induced cell death. Cell Structure and Function 2003; 28:23-29.

[33] Wadia JS, Chalmers-Redman RME, Ju WJH, Carlile GW, Phillips JL, Fraser AD, Tatton WG Mitochondrial membrane potential and unclear changes in apoptosis caused by serum and nerve growth factor withdrawal: time course and modification by (-)-deprenyl. I Neurosci 1998; 18:932947.
[34] Yamahara J, Yamada T, Kimura H, Sawada T, Fujimura $\mathrm{H}$. Biologically activeprinciples of crude drugs :anti-allergic principles of "shoseiryu-to": I. Effect on delayed-type allergy reaction. Yakugaku Zasshi 1982; 102:881-886.

[35] Zamzami NP, Marchetti M, Castedo D, Decaudin AM, Hirsch T, Susin SA, Petti PX, Mignotte B, Kroemer G. Sequential reduction of mithochondrial transmembrane potential and generation of reactive oxygene species in early programmed cell death. $J$ Exp Med 1995; 182:367-377.

[36] Zamzami N, Kroemer G. The mitochondrion in apoptosis: how Pandora's box opens. Nat Rev Mol Cell Biol 2001; 2 (1): 67-71. Review.

[37] Zamzami N, Maisse C, Metivier D, Kroemer G. Measurement of membrane permeability and permeability transition of mitochondria. Methods Cell Biol. 2001; 65; 147-158.

[38] Zamzami N, Metivier D, Kroemer G. Quantitation of mitochondrial transmembrane potential in cells and in isolated mitochondria. Methods Ensymol. 2000; 322; 208-213.

[39] Zhang Q, Zeng X, Guo J, Wang X. Oxidant stress mechanism of homocysteine potentiating Con Ainduced proliferation in murine splenic $\mathrm{T}$ lymphocytes. Cardiovascular Research 2002; 53:10351042.

[40] Rifa'i M, Kawamoto Y, Nakashima I, Suzuki H. Essential roles of $\mathrm{CD}^{+} \mathrm{CD} 122+\mathrm{T}$ cells in the Maintenance of T cell homeostasis. J. Exp. Med. 2004; 200: 1123-1134 